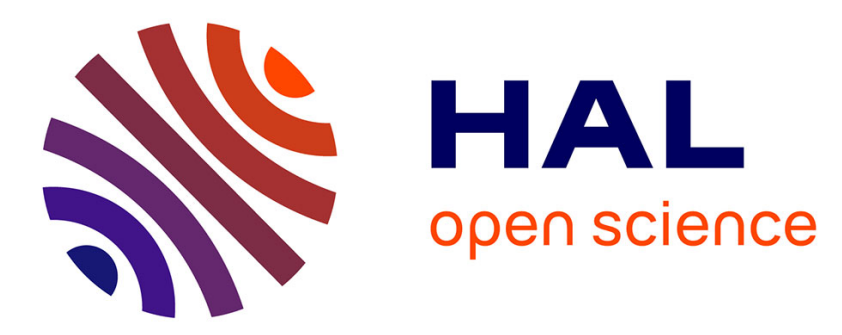

\title{
Role of matrix metalloproteinases and their tissue inhibitors as potential biomarkers of left ventricular remodelling in the athlete's heart
}

Annamaria Vianello, Laura Caponi, Ferdinando Franzoni, Fabio Galetta, Marco Rossi, Marco Taddei, Gino Malvaldi, Pietro Pietrini, Gino Santoro

\section{To cite this version:}

Annamaria Vianello, Laura Caponi, Ferdinando Franzoni, Fabio Galetta, Marco Rossi, et al.. Role of matrix metalloproteinases and their tissue inhibitors as potential biomarkers of left ventricular remodelling in the athlete's heart. Clinical Science, 2009, 117 (4), pp.157-164. 10.1042/CS20080278 . hal-00502879

\section{HAL Id: hal-00502879 \\ https://hal.science/hal-00502879}

Submitted on 16 Jul 2010

HAL is a multi-disciplinary open access archive for the deposit and dissemination of scientific research documents, whether they are published or not. The documents may come from teaching and research institutions in France or abroad, or from public or private research centers.
L'archive ouverte pluridisciplinaire HAL, est destinée au dépôt et à la diffusion de documents scientifiques de niveau recherche, publiés ou non, émanant des établissements d'enseignement et de recherche français ou étrangers, des laboratoires publics ou privés. 


\section{Role of matrix metalloproteinases and their tissue inhibitors as potential biomarkers of left ventricular remodelling in the athlete's heart}

Annamaria Vianello; ${ }^{a}$ Laura Caponi ${ }^{\text {**; }}$ Ferdinando Franzonia; Fabio Galetta ${ }^{a}$; Marco Rossia; Marco Taddei ${ }^{a}$; Gino Malvaldi ${ }^{\text {; }}$ Pietro Pietrini ${ }^{\text {; }}$, Gino Santoro ${ }^{a}$.

a Department of Internal Medicine, University of Pisa, Italy

b Department of Laboratory Medicine and Molecular Diagnostics, Azienda Ospedaliera Universitaria Pisana, University of Pisa, Pisa, Italy

*Corresponding author:

Laura Caponi, Department of Laboratory Medicine and Molecular Diagnostics, Azienda

Ospedaliera Universitaria Pisana, University of Pisa, Via Roma 67, 1-56126 Pisa, Italy.

E-mail: 1.caponi@med.unipi.it; tel.: +39 (050) 2218556; fax:+39 (050) 2218557

Keywords: matrix metalloproteinases; athlete's heart; sports medicine.

Running headline: MMP/TIMP in athletes 


\begin{abstract}
The aim of the present study was to verify whether plasma MMPs and TIMPs could be used as potential markers of paraphysiological remodelling in the athlete's heart, and to correlate these matrix parameters with echocardiographic signs of left ventricular remodelling.
\end{abstract}

Plasma MMP-2 and MMP-9 were measured by zymography, TIMP-1 and TIMP-2 were measured by ELISA in 42 veteran marathoners (AH), and in 25 sedentary healthy subjects (CTL). All subjects were submitted to clinical examination and 2D color Doppler echocardiography together with the measure of circulating NT-proBNP; GGT was evaluated as a marker of cardiovascular disease.

Veteran athletes had significant elevation in LV dimensions and calculated LV mass index. Diastolic and systolic functions were normal for both groups. MMP-9 levels were significantly lower in AH than in CTL (56.9 \pm 4.3 versus $119.4 \pm 21.5 \mathrm{mU} / 1, \mathrm{p}<0.01)$. There were significant differences in MMP2 between the 2 groups, with down-regulation in the AH $(182.5 \pm 16.8 \mathrm{U} / \mathrm{ml}$ in CTL versus 117.1 \pm 9.1 in AH, $\mathrm{p}<0.01)$. MMP-2 and MMP-2/TIMP-2 were inversely correlated to myocardial indices of hypertrophy in AH and CTL. AH and CTL subjects showed similar TIMPs values.

Our results indicate that MMPs and TIMPs could represent potential biomarkers of adaptive heart remodelling in the athletes. In addition, the inverse correlation of the MMP-2/TIMP-2 system with echocardiographic signs of myocardial hypertrophy could represent a new diagnostic and prognostic indicator useful in the evaluation of cardiovascular risk in athletes. 


\section{Introduction}

The condition known as athlete's heart (AH) exhibits paraphysiological remodelling, in particular myocardial parietal hypertrophy and chamber enlargement, due to aerobic endurance sport activity [1]. In this activity, training is accompanied by an elevated inflow of oxygen to the tissues, with a relative shortage of oxygen and an elevated pre-load under stress but adequate haemodynamic and tissue compensation under basal conditions [2]. In contrast, patients with pathological remodelling suffer from inadequate oxygen supply to the tissues and elevated filling pressure even at rest. Habitual aerobic activity also reduces coronary heart disease events, although it may increase the risk of sudden cardiac death and acute myocardial infarction in susceptible athletes $[3,4]$. Paraphysiological and pathological heart remodelling present similar macroscopic, but significantly different microscopic features; in heart failure there is marked fibrosis whereas in $\mathrm{AH}$ there is none, which makes the remodelling process reversible and preserves diastolic and systolic ventricular function [5].

Matrix metalloproteinases (MMPs) and their specific tissue inhibitors (TIMPs) are the main determinants of tissue remodelling in both physiological and pathological processes. Evidence suggests that MMP activity can change the structure of the extra-cellular matrix, leading to the loss of cardiac contractility through proteolysis [6]. The remodelling of collagen fibres and the loss of myocytes is known to cause ventricular enlargement and progressive contractile dysfunction [7]. Left ventricular remodelling in HF patients is also stimulated by degradation of the extra-cellular matrix by MMPs [8]. Gelatinases A and B (MMP-2 and MMP-9) are particularly active in degrading denatured collagen [9] and have been the focus of pathological heart remodelling studies.

While recent data suggests that plasma MMP-2 and MMP-9 could provide diagnostic and prognostic information in patients with heart failure [6], the MMP and TIMP profile in athlete's heart has not yet been investigated even though it presents an excellent model of reversible and adaptive paraphysiological cardiac remodelling [10] that could be useful for comparison studies.

We sought to define and compare the plasma profiles of MMP-2 and MMP-9 and their specific inhibitors in veteran marathoners and in a control group of healthy sedentary subjects, in order to determine whether these endopeptidases could serve as potential markers of adaptative remodelling of the heart. The correlations between these parameters of extracellular matrix turnover and laboratory (NT-proBNP) and echocardiographic signs of left ventricular structure and remodelling were analysed. In our study we also evaluated the values of circulating GGT, emerging as a marker of cardiovascular disease. 


\section{Methods}

\section{Subjects}

Two groups of subjects comparable in age and sex were enrolled in this study (Table 1): 25 sedentary healthy controls and 42 veteran marathoners with athlete's heart.

Veteran marathoners with $\mathrm{AH}$ were recruited from among athletes who come voluntarily once a year to the Azienda Ospedaliera Universitaria Pisana (AOUP) for a cardiologic examination. All of those enrolled were eligible for competitive sport, with no electrocardiographic or echocardiographic signs of hypertrophic cardiomyopathy, diastolic or systolic dysfunction or arrhythmias. All had been training and competing continuously for at least 5 years and had a left ventricular mass (LV mass) $>106 \mathrm{~g} / \mathrm{m}^{2}$. Plasma samples were obtained 48 hours after their most recent training session. None had been under any medical treatment for the last 5 years.

Sedentary controls (CTL) were recruited through primary care physicians.

Each subject provided a medical history and underwent clinical examination, 12-lead electrocardiogram, 2D color Doppler echocardiography, and abdominal echography; chest radiography was performed in cases of smoking, professional risk, or a family history of lung cancer. Marathoners underwent also cycloergometric and spirometric tests. All of the data was recorded in confidential clinical files.

Fasting blood samples obtained on the same day as the examinations were used for the analyses of gelatinase and TIMP concentrations, NT-proBNP, GGT, inflammation indices, and coagulative, hepatic and renal function. Subjects with evidence of neoplastic disease, acute or chronic inflammatory disease, renal and/or hepatic dysfunction, or haemostasis disease were excluded from the study.

Our study was carried out in accordance with the Declaration of Helsinki (2000) of the World Medical Association. The research protocol was reviewed and approved by the AOUP Ethical Committee. All participants gave their written, informed consent on the study procedure and the purposes had been explained to them.

\section{Echocardiography}

Examinations were carried out by two trained echocardiographers, using a Sonos 5500 system with a 4-MHz transducer. A biplanar evaluation of the ejection fractions was carried out, and mono-dimensional measurements of the left diastolic and systolic diameters, and the septal and parietal thicknesses were performed at the chordal level just beneath the mitral valve leaflets, following the American Society of Echocardiography criteria. Measurement of early peak to late peak transmitral flow velocity ratio (E/A ratio) was made in the apical view with a cursor at the mitral valve inflow. The average value based on three consecutive measures (min. to max. variation $<5 \%$ ) was calculated. The LV mass was calculated according to the formula of Devereux et al. [11] and indexed on the basis of individually calculated body surface areas.

\section{Plasma MMP/TIMP measurements}

Gelatinase and TIMP concentrations were measured in heparinized plasma. Each sample was immediately separated and stored at $-70^{\circ} \mathrm{C}$ in multiple aliquots and thawed once, at the time of use.

Gelatinase activity was determined by zymography; proteins at appropriate dilutions were denatured with SDS under non-reducing conditions and then electrophoretically separated in 
an $8 \%$ polyacrylamide gel containing gelatin at $1 \mathrm{mg} / \mathrm{ml}$. Proteins were re-natured by removing SDS, and the gel was incubated for $16-18$ hours at $37^{\circ} \mathrm{C}$ in a buffer that allowed the lytic action of the gelatinases to take place on the gelatin. The gel was then stained with Coomassie Brilliant Blue and gelatinolytic activity appeared as a clear area against the blue background of undegraded gelatin. The images were digitally scanned and activity was quantified based on the curves of known concentrations of gelatinase standards (MMP-9, Roche Applied Science; MMP-2, Boehringer Mannheim) which were run together with the samples. The lytic areas were measured using QuantityOne software (Bio-Rad Laboratories). Activity was expressed in the same units as the standards. TIMP-1 and TIMP-2 were measured by a commercial ELISA kit (Biotrak, Amersham Bioscience) and the MMP2/TIMP-2 and MMP-9/TIMP-9 ratios were calculated to obtain a more exact parameter of the net activity of the gelatinases in the plasma.

\section{NTpro-BNP and GGT}

NTpro-BNP was assayed using an Elecsys kit (Roche). $\gamma$-glutammyl trasnpeptidase (GGT) was measured spectrophotometrically in a Hitachi 917 automatic analyzer (Roche). They were measured as indices of pathological remodeling and cardiovascular risk, respectively.

\section{Statistical analysis}

Non-parametric tests were applied to analyse the data. Between-group comparisons of gelatinase activity and TIMP levels were carried out using the non parametric Mann-Whitney test. The significance level was set at $\mathrm{p}<0.05$. Correlations between the parameters under examination and the gelatinases and their inhibitors was determined for the pooled and single group data by the non-parametric Spearman correlation coefficient. All analysis were performed with Prism 4 (GraphPad Software, La Jolla, CA, USA). 


\section{Results}

\section{Comparison of echocardiogram and plasma parameters between CTL and AH}

Table 1 presents the relevant data for the two groups studied; significant differences emerged on statistical analysis.

Both groups showed values of systolic and diastolic function in the normal range. Nonetheless, AH showed a significantly lower ejection fraction and a higher transmitral flow velocities ratio than CTL. AH subjects had a larger LV mass and significant left ventricular remodelling compared to the controls, with higher values for the left ventricular telediastolic diameter, septal thickness and posterior parietal thickness. Both MMP-2 and MMP-9 were lower in AH than in CTL. The MMP-2/TIMP-2 ratio was significantly lower in AH. There were no significant differences in TIMP-1, TIMP-2, or the MMP-9/TIMP-1 ratio between the two groups.

\section{Correlations between the plasma MMP/TIMP profiles and echocardiogram and laboratory parameters}

Correlations were tested on the pooled data (Table 2). MMP-2 and the MMP-2/TIMP-2 ratio showed a significant inverse correlation with the septal and posterior parietal thicknesses and (to a lesser extent) with the LV mass. A regression curve was designed for each of the mentioned parameter (Figure 1). The MMP-9 and the MMP-9/TIMP-1 ratio, were inversely correlated with the left ventricular telediastolic diameter.

No correlation was evident with GGT levels, while NT-proBNP positively correlated with the LV mass (Spearman $\mathrm{r}=0.2832, \mathrm{p}=0.0312$ ).

\section{Analysis of the data by group (Table 3)}

\subsection{Correlations between MMPs, TIMPs and echocardiogram parameters}

An inverse correlation between the MMP-2 and septal and posterior parietal thickness (as was seen in the pooled data) was found both in the athletes and the controls. A similar correlation was found between the MMP-2/TIMP-2 ratio and septal and posterior parietal thickness in the CTL group while only posterior parietal thickness negatively correlated in athletes.

In AH but not in controls the MMP-9/TIMP-1 ratio was inversely correlated with the telediastolic ventricular diameter (as in the pooled data), while MMP-9 and the MMP9/TIMP-1 ratio were positively correlated with posterior parietal thickness.

\subsection{Correlations between the plasma MMP/TIMP profile and laboratory parameters}

In athletes an inverse relationship was found between MMP-2 and MMP-9 levels (Spearman's r: - 0.4922, p: 0.0027), which was confirmed by an inverse correlation between MMP2 and the MMP-9/TIMP-1 ratio in AH (Spearman's r: -0.4539, p: 0.0117). Moreover, NTproBNP was positively correlated with MMP-2 (Spearman's r: 0.3822, p: 0.0235) and inversely correlated with MMP-9 and MMP-9/TIMP-1 (Spearman's r: -0.3093, p: 0.0491 and r: -0.3583 , p: 0.0319, respectively). In CTL, TIMP-1 was inversely correlated with MMP-9 and TIMP-2 (Spearman's r: -0.4096, p: 0.0469 and r: -0.5017, p: 0.0125, respectively). 


\section{Discussion}

The aim of this study was to investigate whether plasma gelatinases and their tissue inhibitors reflect heart remodelling in athletes, compared to controls. Our principle findings were:

1) MMP-9 are down-regulated in $\mathrm{AH}$ compared to CTL.

2) MMP-2 and MMP-2/TIMP-2 were lower in AH than in CTL.

3) Both in CTL and AH, MMP-2 and MMP-2/TIMP-2 showed an absolute inverse correlation with echocardiographic indices of myocardial hypertrophy.

4) $\mathrm{AH}$ subjects showed an inverse correlations between MMP-9 and the left ventricular diameter.

5) $\mathrm{AH}$ and CTL subjects showed similar TIMPs values.

Plasma levels of MMP-2 and MMP-9, as well as the MMP-2/TIMP-2 ratio, were downregulated in athletes compared to sedentary controls, indicating a reduction in ECM proteolytic activity. Although in AH the levels of both gelatinases were reduced, MMP-2 was inversely correlated with MMP-9 and the MMP-9/TIMP-1 ratio, suggesting differing roles for the two peptidases. Analogous correlations were seen between MMP-2 and MMP-9 and NTproBNP and the echocardiographic parameters; in athletes NTproBNP was positively correlated with MMP-2 and inversely correlated with MMP-9/TIMP-1, while the opposite held true for parietal thickness.

AH subjects exhibited significantly lower MMP-2 and MMP-2/TIMP-2 values than CTL; moreover, we found MMP-2 levels were correlated with echocardiographic parameters of hypertrophy.

Ahmed et al. showed that the MMP-2 values are decreased also in hypertensive cardiac hypertrophy without heart failure [12]. AH and hypertensive heart are both characterized by myocardial hypertrophic remodelling. Studies on animal models have shown that MMP-2 upregulation in the tissues plays a key role in myocardial cardiomyocytic hypertrophy, suggesting that myocardial hypertrophy could be the main determinant of the MMP-2 profile in plasma [13]. Other studies have shown that the MMP-2/TIMP-2 system plays a role in growth and neoangiogenesis processes and that blood flow can modulate MMP-2 expression [14]. At the same time, the high degree of morphological adaptability shown by the capillary network in hypertrophied muscles is well known. Compensatory recapillarization and neoangiogenesis are also seen in atherosclerotic and hypertensive diseases. The presence of MMP-2/TIMP-2 down-regulation in our model of paraphysiological hypertrophic heart remodelling seems to confirm a strong correlation with the processes of cardiomyocytic hypertrophy and cardiovascular neoangiogenesis in the tissues. Further studies to elucidate the apparent discrepancy between the MMP-2 profile in plasma and tissues are needed.

Our data shows that aerobic exercise can lead to lower basal MMP-9 values compared to sedentary controls. MMP9 can be considered an inflammatory marker and we found it positively correlated with other known biomarkers of inflammations as fibrinogen and IL-6 (data not shown). MMP-9 is now also recognized as a marker of cardiovascular risk [15] and a possible marker of plaque evolution and rupture [16]. Moreover, in vivo studies of the zymographic activity of MMP-9 inside the evolving atherosclerotic plaque confirm its role in vascular remodelling. On the other hand, data has been published on the role of diet and exercise in reducing plasma levels of MMP-9 [17]. Inhibition of MMP-9 activity by statins was demonstrated in biopsy samples of aortic aneurysms and carotid plaques $[18,19]$. 
Gullestad et al. confirmed that MMP-9 concentrations are decreased by pharmacologic treatment with statins [20]. The lower MMP-9 levels observed by us in AH might simply reflect decreased remodelling activity, although it should be noted that under certain conditions MMP-9 in the myocardium has a pro-fibrotic effect since it activates pathways and proteins (such as TGF- $\beta 1$ ) that favour ECM deposition [21]. As a consequence, low levels of MMP-9 may cause a basal down-regulation of pro-fibrotic and pro-inflammatory activity in the matrixine system in athletes. Moreover, since strenuous exercise is accompanied by significantly raised MMP-9, troponins, and indices of inflammation, the lack of 'normalization' of plasmatic MMP-9 and inflammatory markers within 48 hours from the end of endurance training could indicate an overtraining cardiovascular syndrome [22].

Our study showed a direct correlatios between MMP-9 and MMP-9/TIMP-1 and parietal thickness in AH, and an inverse correlation with the left ventricular telediastolic diameter. In contrast, Yan et al. reported indications of a positive correlation between MMP-9 and the left ventricular end-diastolic diameter, and a negative correlation between MMP-9 and MMP9/TIMP-1 and left ventricular function in pathological heart remodelling [23]. Therefore, the plasma MMP-9/TIMP-1 ratio could be linked to pathologic remodelling and the risk of left ventricular dysfunction in athlete's heart as well. To confirm this hypothesis, it would be interesting to compare the MMP-9/TIMP-1 ratio and TIMP-1 values in groups of trained and over-trained athletes.

One finding of our study was that AH and CTL subjects showed similar TIMPs values. On the other hand, there have already been reports of higher TIMP-1 values in patients with hypertension, a condition characterized by interstitial fibrosis and myocardial hypertrophy possibly preceding LV dysfunction [25].

Our results are of particular interest, because the two groups studied did not show any difference in NT-proBNP, the most commonly used laboratory index of heart dysfunction [26]. The NT-proBNP, a known parameter correlated to heart failure is similarly distributed in AH or CTL. We decided to evaluated also GGT, because it is a laboratory parameter recently proposed to represent a marker of cardiovascular disease [27], therefore it seemed that its evaluation could be of interest, in particular in athlete's heart subjects, but we did not observe any significant difference between the two groups.

Our data suggest that $\mathrm{AH}$ and CTL have differing plasmatic gelatinase profiles. This study presents some limitations, because plasma levels of MMPs and TIMPs may not reflect cardiac tissue remodelling alone; other physiologic and pathologic conditions are known to affect the concentration and activity of these endopeptidases. Nonetheless, significant differences in these parameters were found between normal subjects and AH. The particularly low basal MMP-9 values detected in AH suggest a mechanism of cardiovascular protection.

Furthermore, this is the first study to show a relationship between plasma matrix biomarkers in $\mathrm{AH}$ and echocardiographic parameters of myocardial hypertrophy. It seems likely that a down-regulation of MMP-2 takes place in conjunction with cardiac paraphysiological hypertrophic remodelling. As specified above, unlike all other laboratory parameters, the plasma profile of gelatinases is quite distinct between $\mathrm{AH}$ and reference controls. This could be useful in evaluating the cardiovascular adaptability of athletes before they engage in strenuous exercise, so that high-risk subjects can be screened out. The addition of these remodelling markers to NT-proBNP and electrocardiographic and echocardiographic data could improve protocols for the evaluation of hypertrophic cardiomyopathy in athletes. Monitoring the plasma profile of remodelling markers over time may also be useful in studying the long-term consequences and significance of marked left ventricular remodelling in AH. Finally, integrating echocardiographic imaging parameters with plasma matrix biomarkers could allow clinicians to identify the switching point between paraphysiological 
and pathological remodelling in athletes, although a larger prospective study will be needed to confirm this.

\section{Funding}

Study supported by grants of University of Pisa

\section{Acknowledgments}

We are grateful to R. Fasano for her laboratory work and to Dr. A. Squadrone for his help in recruiting the veteran marathoners.

\section{Conflict of interest}

None to declare 


\section{References}

1. Pluim B.M., Zwinderman A.H., van der Laarse A., van der Wall E.E. (2000) The athlete's heart. A meta-analysis of cardiac structure and function. Circulation 101, 336-344.

2. Dickhuth H.H., Röcker K., Mayer F., König D., Korsten-Reck U. (2004) Endurance training and cardial adaptation (athlete's heart). Herz 29, 373-380.

3. Maron B.J., Pelliccia A. (2006) The heart of trained athletes: cardiac remodeling and the risks of sports, including sudden death. Circulation 114, 1633-1644.

4. Pelliccia A., Di Paolo F.M., Quattrini F.M., Basso C., Culasso F., Popoli G., De Luca R., Spataro A., Biffi A., Thiene G., Maron B.J. (2008) Outcome in athletes with marked ECG repolarization abnormalities. N. Engl. J. Med. 358, 152-161.

5. McMullen J.R., Jennings G.L. (2007) Differences between pathological and physiological cardiac hypertrophy: novel therapeutic strategies to treat heart failure. Clin. Exp. Pharmacol. Physiol. 34, 255-262.

6. Altieri P., Brunelli C., Garibaldi S., Nicolino A., Ubaldi S., Spallarossa P., Olivotti L., Rossettin P., Barsotti A., Ghigliotti G. (2003) Metalloproteinases 2 and 9 are increased in plasma of patients with heart failure. Eur. J. Clin. Invest. 33, 648-656.

7. D'Armiento J. (2002) Matrix metalloproteinase disruption of the extracellular matrix and cardiac dysfunction. Trends Cardiovasc. Med. 12, 97-101.

8. Spinale F.G. (2002) Matrix metalloproteinases. Regulation and dysregulation in the failing heart. Circ. Res. 90, 520-530.

9. Nagase H., Visse R., Murphy G. (2006) Structure and function of matrix metalloproteinases and TIMPs. Cardiovasc. Res. 69, 562-73.

10. Pelliccia A., Maron B.J., De Luca R., Di Paolo F.M., Spataro A., Culasso F. (2002) Remodeling of left ventricular hypertrophy in elite athletes after long-term deconditioning. Circulation 105, 944-949.

11. Devereux R.B., Alonso D.R., Lutas E.M., Gottlieb G.J., Campo E., Sachs I., Reichek N. (1986) Echocardiographic assessment of left ventricular hypertrophy: comparison to necropsy findings. Am. J. Cardiol. 57, 450-458.

12. Ahmed S.H., Clark L.L., Pennington W.R., Webb C.S., Bonnema D.D., Leonardi A.H., McClure C.D., Spinale F.G., Zile M.R. (2006) Matrix

Metalloproteinases/Tissue Inhibitors of Metalloproteinases. Relationship between changes in proteolytic determinants of matrix composition and structural, functional, and clinical manifestations of hypertensive heart disease. Circulation 113, 20892096.

13. Bergman M.R., Teerlink J.R., Mahimkar R., Li L., Zhu B.Q., Nguyen A., Dahi S., Karliner J.S., Lovett D.H. (2007) Cardiac matrix metalloproteinase-2 expression independently induces marked ventricular remodeling and systolic dysfunction. Am. J. Physiol. Heart Circ. Physiol. 292, H1847-1860.

14. Bassiouny H.S., Song R.H., Hong X.F., Singh A., Kocharyan H., Glagov S. (1998) Flow regulation of $72-\mathrm{kD}$ collagenase IV (MMP2) after experimental arterial injury. Circulation 98, 157-163.

15. Blankenberg S., Rupprecht H.J., Poirier O., Bickel C., Smieja M., Hafner G., Meyer J., Cambien F., Tiret L.; AtheroGene Investigators. (2003) Plasma concentrations and genetic variation of matrix metalloproteinase 9 and prognosis of patients with cardiovascular disease. Circulation 107, 1579-1585. 
16. Robertson L., Grip L., Mattsson Hulten L., Hulthe J., Wiklund O. (2007) Release of protein as well as activity of MMP-9 from unstable atherosclerotic plaques during percutaneous coronary intervention. J. Intern. Med. 262, 659-667.

17. Niessner A., Richter B., Penka M., Steiner S., Strasser B., Ziegler S., Heeb-Elze E., Zorn G., Leitner-Heinschink A., Niessner C., Wojta J., Huber K. (2006) Endurance training reduces circulating inflammatory markers in persons at risk of coronary events: impact on plaque stabilization? Atherosclerosis 186, 160-165.

18. Evans J., Powell J.T., Schwalbe E., Loftus I.M., Thompson M.M. (2007) Simvastatin attenuates the activity of matrix metalloprotease- 9 in aneurysmal aortic tissue. Eur. J. Vasc. Endovasc. Surg. 34, 302-303.

19. Stintzing S., Heuschmann P., Barbera L., Ocker M., Jung A., Kirchner T., Neureiter D. (2005) Overexpression of MMP9 and tissue factor in unstable carotid plaques associated with Chlamydia pneumoniae inflammation and apoptosis. Ann. Vasc. Surg. 19, 310-319.

20. Gullestad L., Oie E., Ueland T., Yndestad A., Aukrust P. (2007) The role of statins in heart failure. Fund. Clin. Pharmacol. 21(Suppl.2), 35-40.

21. Spinale F.G. (2007) Myocardial matrix remodeling and the matrix metalloproteinases: influence on cardiac form and function. Physiol. Rev. 87, 12851342.

22. Saenz A.J., Lee-Lewandrowski E., Wood M.J., Neilan T.G., Siegel A.J., Januzzi J.L., Lewandrowski K.B. (2006) Measurement of a plasma stroke biomarker panel and cardiac troponin $\mathrm{T}$ in marathon runners before and after the 2005 Boston Marathon. Am. J. Clin. Pathol. 126, 185-189.

23. Yan A.T., Yan R.T., Spinale F.G., Afzal R., Gunasinghe H.R., Arnold M., Demers C., McKelvie R.S., Liu P.P. (2006) Plasma Matrix Metalloproteinase-9 level is correlated with left ventricular volumes and ejection fraction in patients with heart failure. J. Card. Fail. 12,514-519.

24. Chandrasekar B., Mummidi S., Mahimainathan L., Patel D.N., Bailey S.R., Imam S.Z., Greene W.C., Valente A.J. (2006) Interleukin-18-induced human coronary artery smooth muscle cell migration is dependent on NF-kappaB- and AP-1mediated matrix metalloproteinase- 9 expression and is inhibited by atorvastatin. J. Biol. Chem. 281, 15099-15109.

25. Tayebjee M.H., Nadar S.K., MacFadyen R.J., Lip G.Y. (2004) Tissue inhibitor of metalloproteinase-1 and matrix metalloproteinase-9 levels in patients with hypertension. Relationship to tissue Doppler indices of diastolic relaxation. Am. J. Hypertens. 17, 770-774.

26. Masson S, Latini R, Anand IS, Barlera S, Angelici L, Vago T, Tognoni G, Cohn JN, Val-HeFT Investigators. (2008) Prognostic value of changes in N-terminal probrain natriuretic peptide in Val-HeFT (Valsartan Heart Failure Trial). J. Am. Coll. Cardiol. (12), 997-1003.

27. Lee D.S., Evans J.C., Robins S.J., Wilson P.W., Albano I., Fox C.S., Wang T.J., Benjamin E.J., D'Agostino R.B., Vasan R.S. (2007) Gamma glutamyl transferase and metabolic syndrome, cardiovascular disease, and mortality risk: the Framingham Heart Study. Arterioscler.Thromb. Vasc. Biol. 27, 127-133. 


\begin{tabular}{|c|c|c|}
\hline & $\begin{array}{l}\text { Healthy controls } \\
n^{\circ} 25\end{array}$ & $\begin{array}{l}\text { Athletes } \\
n^{\circ} 42\end{array}$ \\
\hline Age, yrs & $57 \pm 2$ & $58 \pm 1$ \\
\hline $\operatorname{Sex}, \mathbf{M} / F$ & $16 / 9$ & $40 / 2$ \\
\hline $\begin{array}{l}\text { Systolic blood } \\
\text { pressure, mmHg }\end{array}$ & $\begin{array}{c}135 \pm 2 \\
(131-139)\end{array}$ & $\begin{array}{c}134 \pm 1 \\
(131-137)\end{array}$ \\
\hline $\begin{array}{l}\text { Diastolic blood } \\
\text { pressure, } \mathrm{mmHg}\end{array}$ & $\begin{array}{c}78 \mathrm{c} 2 \\
(75-81) \\
\end{array}$ & $\begin{array}{c}76 \pm 1 \\
(75-78) \\
\end{array}$ \\
\hline $\begin{array}{l}\text { EF } \\
\%\end{array}$ & $\begin{array}{c}65.0 \pm 0.39 \\
(64.6-66.3)\end{array}$ & $\begin{array}{c}61.5 \pm 0.6 * * * \\
(59.5-62.0)\end{array}$ \\
\hline E/A ratio & $\begin{array}{c}1.0 \pm 1.08 \\
(0.85-1.08) \\
\end{array}$ & $\begin{array}{c}1.7 \pm 0.07 * * * \\
(1.62-1.89) \\
\end{array}$ \\
\hline $\begin{array}{l}\text { GammaGT } \\
\text { U/L }\end{array}$ & $\begin{array}{c}24.4 \pm 3.1 \\
(18.1-30.7)\end{array}$ & $\begin{array}{c}27.4 \pm 1.7 \\
(23.9-30.9)\end{array}$ \\
\hline $\begin{array}{l}\text { NTproBNP } \\
\mathrm{pg} / \mathrm{ml}\end{array}$ & $\begin{array}{c}52.3 \pm 9.7 \\
(32.3-72.3) \\
\end{array}$ & $\begin{array}{c}39.3 \pm 4.2 \\
(30.9-47.7) \\
\end{array}$ \\
\hline $\begin{array}{l}\text { MMP2 } \\
\text { U/ml }\end{array}$ & $\begin{array}{c}182.5 \pm 16.8 \\
(147.7-217.4)\end{array}$ & $\begin{array}{l}117.1 \pm 9.1 * * \\
(98.6-135.6)\end{array}$ \\
\hline $\begin{array}{l}\text { MMP9 } \\
\mathrm{mU} / \mathbf{l}\end{array}$ & $\begin{array}{c}119.4 \pm 21.5 \\
(74.9-163.8)\end{array}$ & $\begin{array}{l}56.9 \pm 4.3 * * \\
(48.2-65.6)\end{array}$ \\
\hline $\begin{array}{l}\text { TIMP2 } \\
\mathrm{ng} / \mathrm{ml}\end{array}$ & $\begin{array}{c}162.4 \pm 5.1 \\
(151.9-173.0)\end{array}$ & $\begin{array}{c}173.4 \pm 6.0 \\
(161.2-185.6)\end{array}$ \\
\hline $\begin{array}{l}\text { TIMP1 } \\
\text { ng/ml }\end{array}$ & $\begin{array}{c}228.3 \pm 11.7 \\
(204.0-252.7)\end{array}$ & $\begin{array}{c}230.8 \pm 9.5 \\
(211.6-250.1)\end{array}$ \\
\hline MMP2/TIMP2 & $\begin{array}{c}1.13 \pm 0.10 \\
(0.91-1.34)\end{array}$ & $\begin{array}{c}0.66 \pm 0.05 * * * \\
(0.55-0.76)\end{array}$ \\
\hline МMP9/TIMP1 & $\begin{array}{c}0.65 \pm 0.16 \\
(0.33-0.97)\end{array}$ & $\begin{array}{l}0.27 \pm 0.03 * \\
(0.21-0.32) \\
\end{array}$ \\
\hline $\begin{array}{l}\text { Indexed LV mass } \\
\mathrm{g} / \mathrm{m}^{2}\end{array}$ & $\begin{array}{c}90.8 \pm 5.2 \\
(79.6-101-9)\end{array}$ & $\begin{array}{l}130.1 \pm 2.6^{* * * *} \\
(124.9-135.4)\end{array}$ \\
\hline $\begin{array}{l}\text { Septal thickness } \\
\text { cm }\end{array}$ & $\begin{array}{c}1.04 \pm 0.04 \\
(0.95-1.12) \\
\end{array}$ & $\begin{array}{c}1.18 \pm 0.02 * * \\
(1.15-1.21)\end{array}$ \\
\hline $\begin{array}{l}\text { Parietal thickness } \\
\text { cm }\end{array}$ & $\begin{array}{c}0.93 \pm 0.04 \\
(0.83-1.02)\end{array}$ & $\begin{array}{c}1.07 \pm 0.02 * * \\
(1.03-1.11)\end{array}$ \\
\hline $\begin{array}{l}\text { LVEDD } \\
\text { cm }\end{array}$ & $\begin{array}{c}4.83 \pm 0.1 \\
(4.62-5.04)\end{array}$ & $\begin{array}{l}5.3 \pm 0.07 * * \\
(5.15-5.44)\end{array}$ \\
\hline
\end{tabular}

Table 1. Main demographic characteristics, MMP and TIMP levels, and echographic parameters for the two groups of subjects.

Data are expressed as means \pm SEM ( $95 \%$ confidence intervals are indicated between parentheses). $* * * \mathrm{p}<0.001$ vs controls, ${ }^{* *} \mathrm{p}<0.01$ vs controls, $* \mathrm{p}<0.05$ vs controls.

EF: ejection fraction; E/A ratio: early peak/late peak transmitral flow velocity ratio; IndLVM: indexed LV mass; Sept thick: septal thickness; PP thick: posterior parietal thickness; LVEDD: telediastolic ventricular diameter. 


\begin{tabular}{lcccc}
\hline & IndLVM & Sept thick & PP thick & LVEDD \\
\hline \multirow{2}{*}{ MMP-2 } & -0.3692 & -0.5548 & -0.6248 & -0.0360 \\
& $\mathbf{0 . 0 0 9 0}$ & $<\mathbf{0 . 0 0 0 1}$ & $<\mathbf{0 . 0 0 0 1}$ & 0.8061 \\
\hline \multirow{2}{*}{ TIMP-2 } & -0.0971 & -0.0533 & -0.0204 & -0.1971 \\
& 0.4978 & 0.7102 & 0.8872 & 0.1656 \\
\hline \multirow{2}{*}{ MMP-2/TIMP-2 } & -0.3440 & -0.4301 & -0.5391 & -0.0024 \\
& $\mathbf{0 . 0 2 2 2}$ & $\mathbf{0 . 0 0 3 6}$ & $\mathbf{0 . 0 0 0 2}$ & 0.9878 \\
\multirow{2}{*}{ MMP-9 } & -0.2581 & -0.08625 & 0.1335 & -0.3015 \\
& 0.0548 & 0.5274 & 0.3268 & $\mathbf{0 . 0 2 4 0}$ \\
\hline \multirow{2}{*}{ TIMP-1 } & 0.0093 & -0.0688 & -0.0130 & 0.1169 \\
& 0.9482 & 0.6316 & 0.9278 & 0.4139 \\
\hline \multirow{2}{*}{ MMP-9/TIMP-1 } & -0.2491 & -0.0841 & 0.0888 & -0.2931 \\
& 0.0779 & 0.5576 & 0.5354 & $\mathbf{0 . 0 3 6 9}$ \\
\hline
\end{tabular}

Table 2. Correlations between MMPs, TIMPs, and echocardiographic parameters for the pooled data.

The first number in the cell indicates the Spearman $r$ coefficient and the second the $p$ value; $p$ values above the significance level are reported in boldface.

IndLVM: indexed LV mass; Sept thick: septal thickness; PP thick: posterior parietal thickness; LVEDD: telediastolic ventricular diameter. 
(a) AH group

\begin{tabular}{lcccc}
\hline & Ind LVM & Sept thick & PP thick & LVEDD \\
\hline \multirow{2}{*}{ MMP-2 } & -0.1028 & -0.4174 & -0.5603 & 0.1444 \\
& 0.5568 & $\mathbf{0 . 0 1 2 6}$ & $\mathbf{0 . 0 0 0 5}$ & 0.4081 \\
\hline \multirow{2}{*}{ TIMP-2 } & -0.3466 & -0.1008 & -0.1024 & -0.3192 \\
& $\mathbf{0 . 0 3 5 6}$ & 0.5528 & 0.5466 & 0.0542 \\
\hline \multirow{2}{*}{ MMP-2/TIMP-2 } & 0.1591 & -0.1607 & -0.3834 & 0.3107 \\
& 0.4009 & 0.3963 & $\mathbf{0 . 0 3 6 5}$ & 0.0947 \\
\multirow{2}{*}{ MMP-9 } & -0.0920 & 0.1481 & 0.4467 & -0.3106 \\
& 0.5624 & 0.3494 & $\mathbf{0 . 0 0 3 0}$ & $\mathbf{0 . 0 4 5 3}$ \\
TIMP-1 & 0.1612 & -0.0673 & -0.0265 & 0.2826 \\
& 0.3405 & 0.6920 & 0.8765 & 0.0901 \\
\hline \multirow{2}{*}{ MMP-9/TIMP-1 } & -0.1430 & 0.1211 & 0.3639 & -0.3266 \\
& 0.3985 & 0.4752 & $\mathbf{0 . 0 2 6 8}$ & $\mathbf{0 . 0 4 8 5}$ \\
\hline
\end{tabular}

(b) CTL group

\begin{tabular}{ccccc}
\hline & IndLVM & Sept thick & PP thick & LVEDD \\
\hline \multirow{2}{*}{ MMP-2 } & -0.3143 & -0.6023 & -0.7503 & 0.3907 \\
& 0.2738 & $\mathbf{0 . 0 2 2 7}$ & $\mathbf{0 . 0 0 2 0}$ & 0.1672 \\
\hline \multirow{2}{*}{ TIMP-2 } & -0.1868 & -0.0133 & -0.1399 & -0.1776 \\
& 0.5225 & 0.9639 & 0.6335 & 0.5436 \\
\hline \multirow{2}{*}{ MMP-2/TIMP-2 } & -0.2508 & -0.5429 & -0.6089 & 0.3333 \\
& 0.3871 & $\mathbf{0 . 0 4 4 9}$ & $\mathbf{0 . 0 2 0 8}$ & 0.2442 \\
\hline \multirow{2}{*}{ MMP-9 } & 0.1604 & 0.0400 & -0.1243 & 0.3752 \\
& 0.5838 & 0.8920 & 0.6720 & 0.1863 \\
\hline \multirow{2}{*}{ TIMP-1 } & -0.4374 & -0.3622 & 0.0932 & -0.2597 \\
& 0.1178 & 0.2031 & 0.7512 & 0.3699 \\
\hline \multirow{2}{*}{ MMP-9/TIMP-1 } & 0.1912 & 0.1600 & -0.1576 & 0.2886 \\
& 0.5126 & 0.5848 & 0.5905 & 0.3170 \\
\hline
\end{tabular}

Table 3. Correlations between MMPs, TIMPs and echocardiographic and laboratory parameters analysed in AH (a) and CTL (b) groups.

The first number in the cell indicates the Spearman $r$ coefficient and the second the $p$ value; $p$ values above the significance level are reported in boldface

IndLVM: indexed LV mass; Sept thick: septal thickness; PP thick: posterior parietal thickness; LVEDD: telediastolic ventricular diameter. 

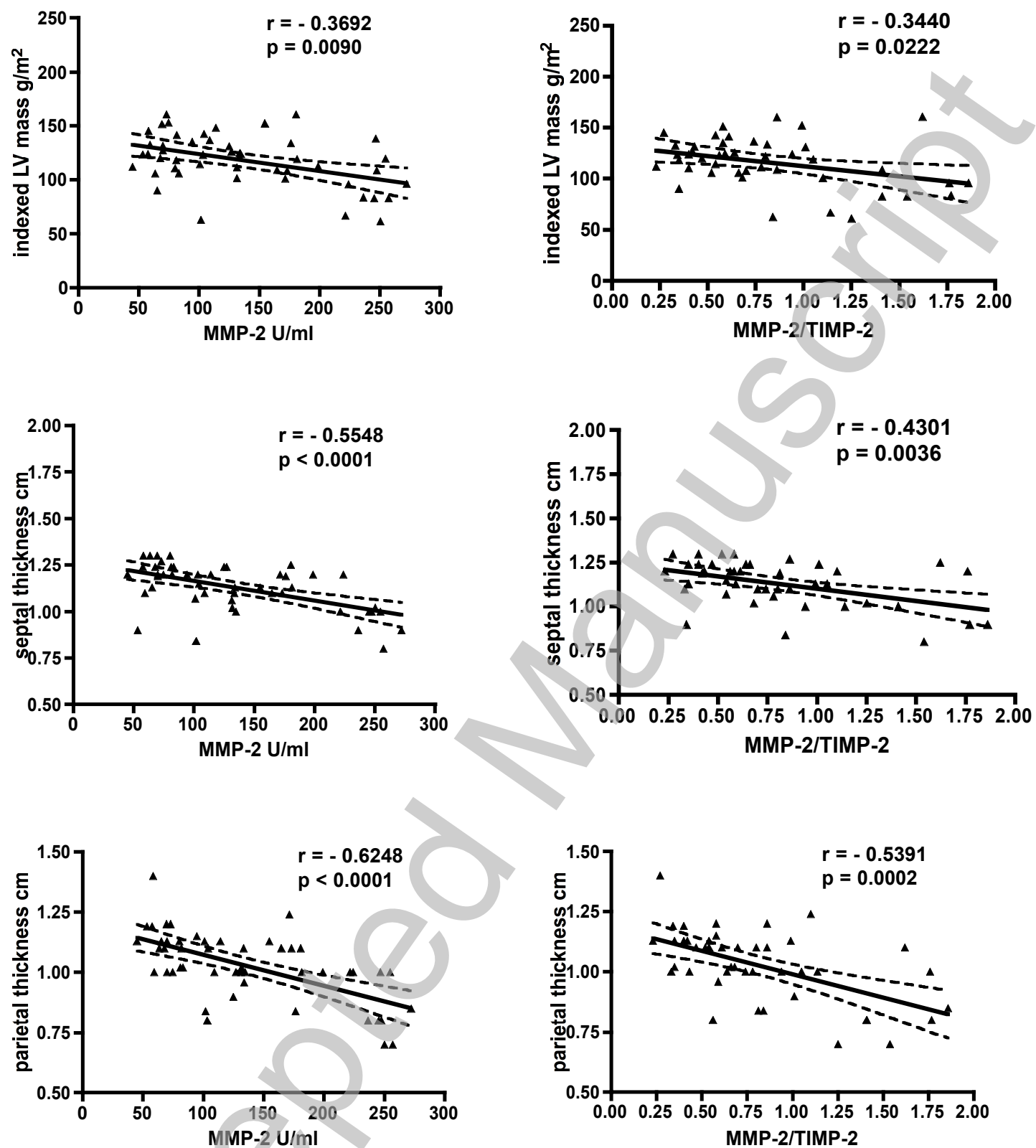

Figure 1. Regression curves between the pooled MMP2 and MMP2/TIMP2 values and echocardiographic parameters. 